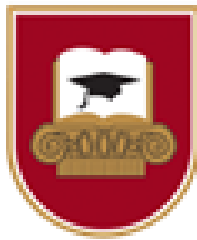

Vadyba

Journal of Management

2020, № 1 (36)

ISSN 1648-7974

\title{
ANTHROPOGENY: HUMAN QUALITY VIRTUAL LEAP
}

\author{
Stasys Paulauskas \\ Strategic Self-Management Institute
}

\begin{abstract}
Not seeing to great achievements of humanity on investigating and discovering of the Universe, a Human still the least understood part of the World But we still more and more need to understand it, its Past, Nowadays and especially - the Future. Virtualics as metatheory of informational World and virtual modelling methodology opens opportunities to construct Human's quality leap in World's development spiral.

From qualitative development point of view the Anthropogony is stated and applied in this research as the science on human origin and development laws and its realisation mechanisms. The HSS spiral is perfect template for further investigation of Human development features and forecasts various scenarios of the Future. Fifth decade going on introspective investigation and creation of quantitative virtual modelling methodology enabled to recognise the Speech as form, the Free creative activity as content of Homo sapiens sapiens. Visual virtual communication replaces speech and become the form of next $-5^{\text {th }}$ Life's quality - Homo Virtualis, which is synthesising trough pull of spiritual bodies of humans into united smart loving brain around 2050 year. Discovered and modelled human's self-regulation cycle enables understand his development mechanisms, what becomes as tool for Artificial intelligence applying into technological and social systems.

KEY WORDS: anthropogeny; virtualics; Human quality leap; Homo Virtualis; Life quality leap; Artificial Intelligence.
\end{abstract}

\section{Introduction}

The main problem. Not seeing to great achievements of humanity on investigating and discovering of the Universe, a Human still the least understood part of the world. But we still more and more need to understand it, his Past, Nowadays and especially - the Future.

Occurred form previous forms of the life Human firstly started to understand surrounding World through deepening into outside to him structure and features of micro and macro physical reality. At micro direction genial human's genome enabled to deepening into mater and find here cells, atoms, elementary particles, quarks, etc. Moreover, human learned how to decompose and synthesise material objects. At macro level he discovered planets, its system, galaxies, metagalaxies, universe, etc. Big-bang, black holes, gravitation waves and other features o Universe enabled to create courageous hypotheses about the past of physical World. However, the future of entire World still big secret for physically clever humanity.

Otherwise, only after understanding physical World human decided to look in to a mirror and ask who I am myself? However Physical and Metaphysical, nor Dialectic methodology didn't answer to this question. Because human is eclectic multi-substantial subject. His organism accepted like physical body, which is also deeply investigated. However, his informational side - soul, spirit, personality still undiscovered parts of a Human. Scholastic science tries to understand such structures from physical and metaphysical points of view, but such methodological tools aren't appropriate for this special deal. The unified Human science don't exist. Several scientific disciplines are investigating and studying a Human: biology, anatomy, physiology, psychology, anthropology, etc. using specific approaches and methodologies. Without united appropriate methodology they look like blinds, touching different parts of elephant's body, what don't give opportunity to see whole this big animal. Human can disconnect, to analyse different his parts, but holistically to collect it again isn't able. It's evident need some holistic methodology able to connect eclectic parts of a human.

We still not sure on origin of human and especially - what is the most important to us - on his future, which will be next quality of Human in parade of life's quality leaps: microorganism, plant, animal, human, ...? We don't satisfy and aren't free traveling in history don't knowing our future. Face to global nowadays challenges related to global warming, climate change, wars, international terrorism, epidemies, poverty, etc. seeking to joint all human civilisation towards save ourselves we need clear and true picture of World development from a Past and until a Future.

Virtualics as metatheory of informational World and virtual modelling methodology opens opportunities to construct Human's quality leap in World's development spiral (S. Paulauskas, 1999). Quantitative Anthropogeny as science on origin and development of a Human occurred many years ago. The term anthropogeny was used in the 1839 edition of Hooper's Medical Dictionary ${ }^{[1]}$ and was defined as "the study of the generation of man". The term was popularized by Ernst Heinrich Haeckel (1834-1919), a German naturalist and zoologist. However, uncertainty of historic empirical data keeps this science in permanent 
change. Quantitative approach always leads deepening into details, e.g. genome, where number of white places not shortening but increasing. Quantitative approach doesn't let's "to see a forest behind threes". Because quantitative human development laws and regularities still uncertain and they can't be used for extrapolation and forecast of a Future.

Virtualics as metatheory of informational World and qualitative virtual modelling methodology opens opportunities to construct Human's quality leap in World's development spiral (S. Paulauskas, 1999). This work is operating just fifth decade - from 1976. Firstly introspection, as psychological method of own operation, investigation was used by author. This enabled to discover Human's self-regulation mechanism in 1979. After creation by author of Dialectical modelling methodology in 1985 and started to construct formalised World development spiral, Humans development quality leap was closest and best-known part of overall spiral.

From qualitative development point of view the Anthropogony (anthropos - human; genie - origin, development; Greek) is the science on human origin and development laws and its realisation mechanisms Multilateral modelling of human's quality leap enabled to define his form, content, contradiction and construct his part of a Life development spiral (Stasys Paulauskas, 1999) The HSS spiral is perfect template for further investigation of Human development features and forecasts various scenarios.

Main subject of this article is Human quality leap location on Life's development spiral.

Main aim of the article is to present virtual model of Human's quality development leap and its selfregulation mechanism.

Main tasks are:

1. To define the form, content and contradiction of Homos sapiens sapiens.

2. To define the form, content and contradiction of Homo Virtualis

3. To present human's development selfregulation mechanism.

\section{From Homo sapiens to Homo sapiens sapiens}

Human historic place covers two last quality stages of Life quality leap, which consist of development stages of: Microorganism, Plant, Animal, Homo sapiens sapiens, Homo Virtualis. The form of nowadays humans is Homo sapiens sapiens (HSS) and it means a homo, who thinks that he thinks. Neighbourhood of our ancestors - Homo Neanderthals is named as Homo sapiens (HS), because he thought, but couldn't understand, that he is thinking, same as each individuum from previous forms of life.

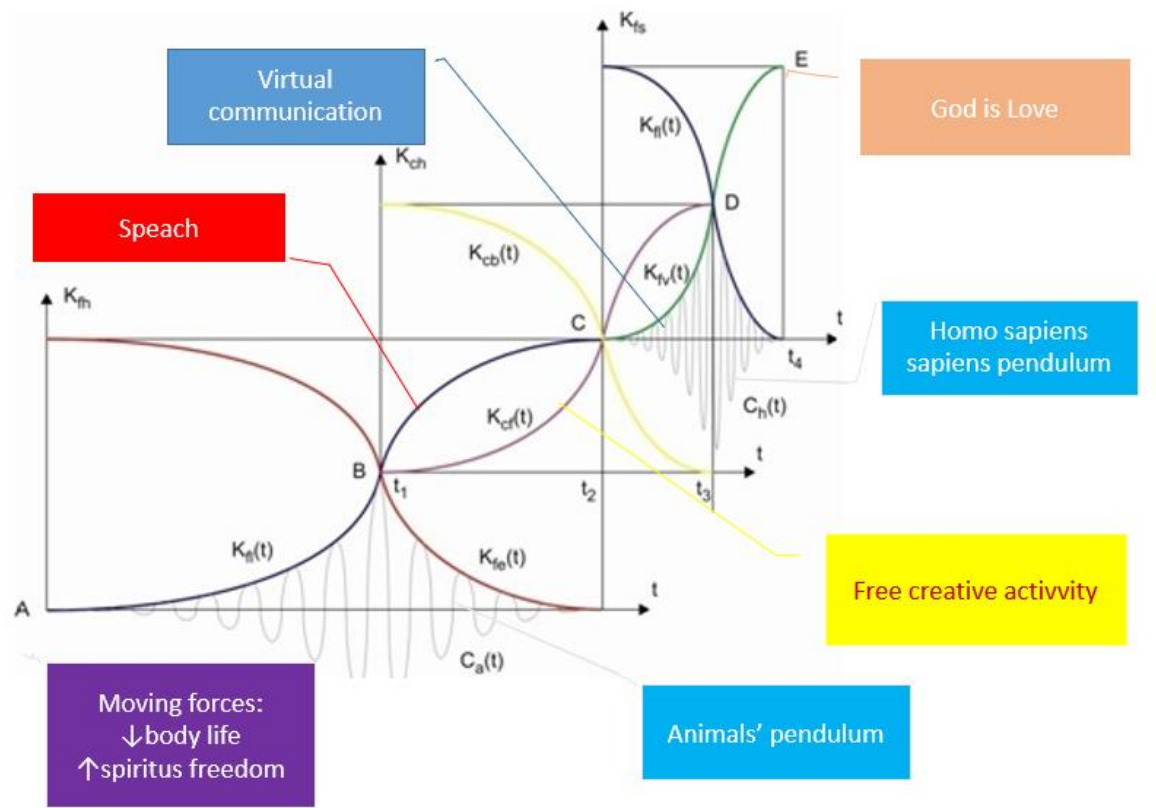

Fig. 1. Human quality leap (Stasys Paulauskas, 1999)

The core ability for ,thinking that thinking" was developed during millions of years accordingly to Speech quality leap $\mathrm{K}_{\mathrm{f}}(\mathrm{t})$ (Figure 1). Starting from point $\mathrm{A}$ animals were developed on ability to generate and send voice, visual and other signs of mental images of a reality in its brains, which enabled target opposite sex receivers to hear a signal on place of signal sender. During history from lower to higher modernised signals animals improved efficiency of such signalisation. The form and content of such important messages becomes more complex and attractive to communicating sides. At HSS stage we understand this like songs and music, which makes to as special impact. However, such musical letters enabled HSS to understand a sense of a telegram and occurring all sense mental images and promising feelings. Brains of chimpanzee can understand more as 600 hundred words, used by American dumbs, but absent of speech organs keeps this clever animal at before HS stage. We could believe, that Homo Neanderthals was able to use separate voice signs as words.

In historic point $\mathrm{B}$ in result of accumulated mutations in body of common for all HSS Grand Mather she started to talk connecting series of words - 
occurred the Speech. Speech is communication mean by sending and accepting verbally encoded with words

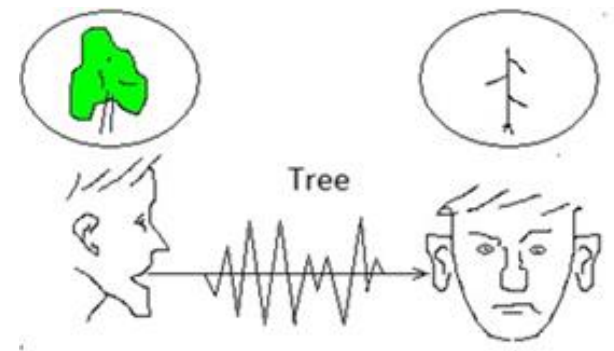

and sentences mental images (Figure 2).

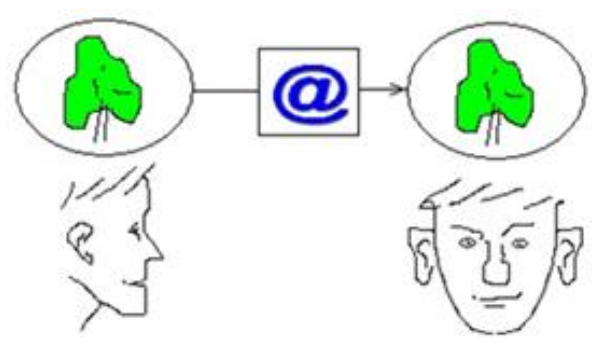

Fig. 2. Sense and transition of human communication (Stasys Paulauskas, 1999)

The speech continues passively - decelerating developing in HSS stage between points B and C. Here we expect saturation of speech quality - new languages don't occurs, some of them disappears. We can do conclusion, that in historic point $\mathrm{C}$ speech is finishing own role in HSS development.

The speech is the form of HSS, which discovered great opportunities to occur new content of animal's exclusive interaction with surrounding - Free creative activity $-\mathrm{K}_{\mathrm{cf}}(\mathrm{t})$, which replace old one - Obligatory work quality $-\mathrm{K}_{\mathrm{co}}(\mathrm{t})$. Obligatory work of HSS we understand as activity necessary for cover actualised demands, especially for physical body maintaining. It is specific content of an animal. Free creative activity is defined by necessity to cover higher demands, related to spiritual needs of HSS. Progressive content of HSS is increasing Free creative activity, what means reducing of manual work.

\section{From Homo sapiens sapiens to Homo virtualis}

Historic point $\mathrm{C}$ marks boring of new kind of communication by virtual images, which replace speech due its weak points - uncertainty and inefficiency, because for transferring mental images long time is needed. Anthropogony discovers opportunity to answer question on reason of computers and internet entering in HSS life. Yes, the mission of such informational converters is to replace speech by direct transferring of mental images between communicating sides. Speech is no needed more, when mental images flights at light speed in internet.

Trough contradiction between spiritual HSS seek to be free and from insertion of physical body total replacing of speech by virtual images takes time between historic points $\mathrm{C}$ and $\mathrm{D}$.

Time point $D$ marks occurring of the last $-5^{\text {th }}$ quality of the Life - Homo virtualis (HV). Physical body disappears. All spiritual - informational bodies of humans connect in a mega brain, in which single human's brain will ply role of a neuron of Homo virtualis. It's significant, because in point $D$ we see convergence of scientific and religion approaches to future of HSS. HV starts his historic path as very smart, free and loving live spiritual organism. The time distance between points C and D depends of HSS abilities to create technical solutions for to connect HSS brains directly to internet. We see how personal computer is nearing close and closer to HSS visual nerve trough virtual oculars and implants. Internet increases speed of transferring of bigger and bigger amounts of information necessary for transferring of mental images. Internet goes to satellite space and is nearing to vacuum energy sources. Considering active - exponential growth of virtual communication, we can provide, that all HSS will be connected to internet all 24 hours per day until 2050 year.

\section{Human development mechanism}

During introspective investigation of scope of human activities, the operating human development mechanism was discovered. Seem, it is applied larger and is applicable for all animals, plants and microorganisms. But understanding of such mechanism could give key for creation of an Artificial Intelligence tools to apply its in robotic, smart and virtual systems.

Alive organism is designed to act answering to some stimulus - demands, incorporated in genome. HSS demand structure is significantly developed comparing to animals thanks to spiritual body development. Start point of each HSS action is actualisation in an organ (stomach) and recognising by brain of a demand at time point $t_{\mathrm{o}}$. Firstly, its' visiting to experience storage field in brain, where all used and expected action programmes are located and marked by efficiency - pleasure signs. Efficient programmes are located closer for repeating use. Normally HSS considers few alternative action programmes and goes with them to Action programming stage, where he is trying to spin each of such programmes in brain simulation. Results of simulation enables to range priorities and modify of such programmes, considering concrete conditions of the action.

At time moment $t_{1}$ they will decide, which alternative action programme must be implemented. The choice is implementing on the base of economic criteria, giving priority to this programme, which enable to cover actualised demand by lowest expenditure of own time and energy. Economy of HSS' time and energy for cover actualised demands is core principle in personal life and in society too as Economy, Economics paradigm. 


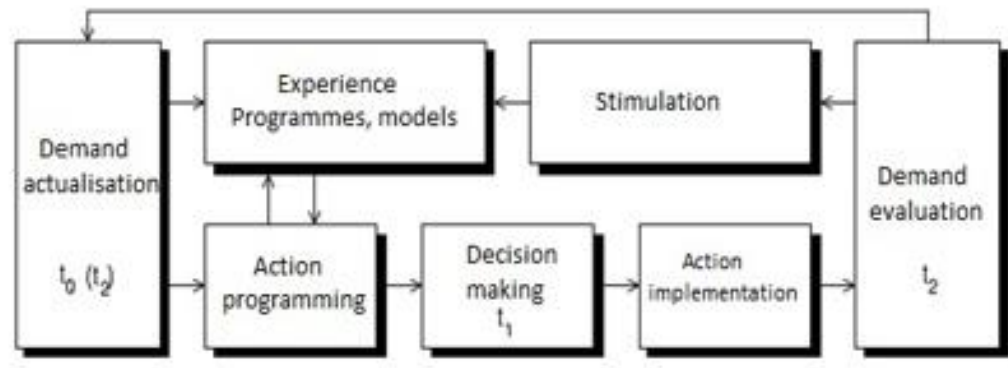

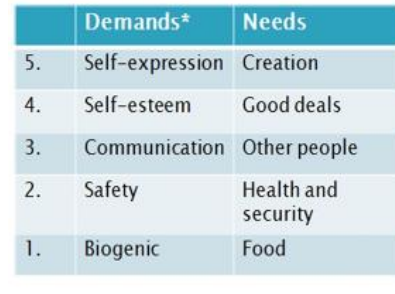

*A.Maslow

Fig. 3. Human self-regulation mechanism (Stasys Paulauskas, 1999) and

A. Maslow' human demand hierarchy

After implementing of chosen programme in time point $t_{2}$ goes assessment of covering of the demand. If unsatisfactory state disappears, positive pleasure senses are producing in a Simulation zone of brain, used efficient programme is indexing by pleasure senses and colours and it is placing in close for repeatable use zone, higher demands occurs. And opposite - if unsatisfactory state not disappears, the demands still not covered and unsatisfaction increases. At this case brain activates negative feelings and used programme is indexing as not efficient and placing in far of repeatable use zone. Not covered demand need to return to the beginning of this cycle, to collect new set of alternative programme and repeat passed steps. So, such clever mechanism assures necessity to develop - rate and select more and more efficient action programmes. It means learning from own practice. Education is special activity, dedicated to fill in programme store with experience of other people, groups, generations, etc.

As more times HSS turns such self-development loop, as higher abilities act efficiently and with pleasure. However, humans are also inventive subjects. Seeking to avoid difficult learning work they invented how pleasure could be directly stimulated by drugs, alcohol, smokes and another fictive stimulus. The time during which human is under action of a drug is free from operating development ring and means degradation. Because all surrounding people still developing.

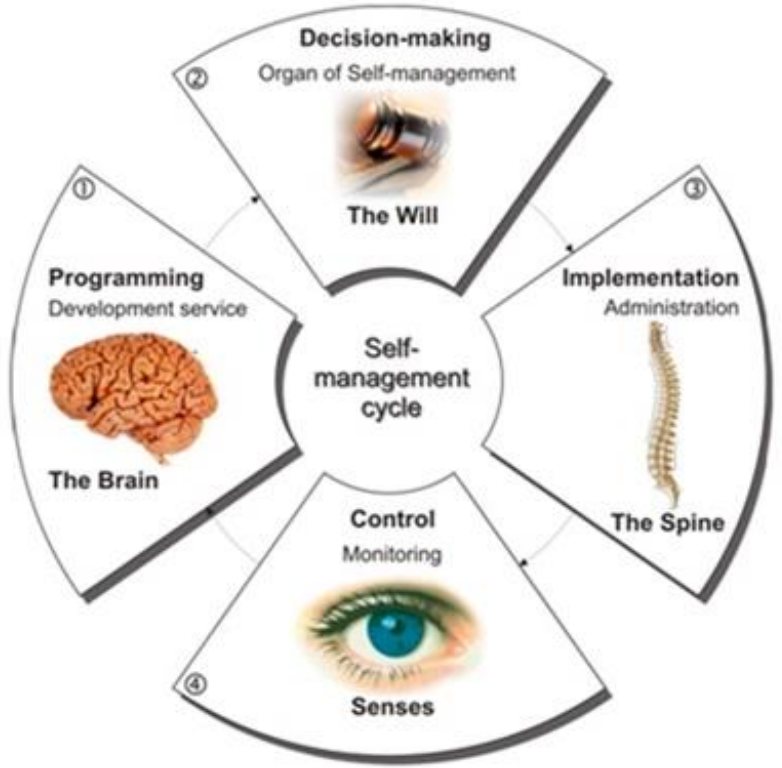

Fig. 4. Human Self-Management cycle (Stasys Paulauskas, 1999)

Discovered HSS development mechanism enabled to describe the sense of Artificial intelligence, which is very important now seeking to create smart and virtual robotic system. Original Intelligence means Human's intelligence especially connected to head brain mental activities, e.g. recognition of faces, words, sentences, etc. Discovered HSS development mechanism shows, that his self-regulation cycles aren't limited on head brain operation only, but includes also Will as decision-making function, Spine as implementation of chosen action program functions and Senses as function of Control of efficiency operation of overall loop of HSS Self-regulation.

We largely applied HSS Self-Management cycle in different social organisations, where this loop has sense of Democracy - the bests practically operating division and connection of different functions of an social organisation. The original democracy is perfect tool for assess democracy in every business and social organisation and avoid fake interpretation of such important institutional order, what nowadays become very important challenge. Introduction of original democracy in social organisations is right way to take 
out features of autocracy and open opportunities to rapid development of societies trough assuring obligatory introduction of innovations, as it is in human organism. Original democracy is very efficient tool for accelerate Humanity development and take out different problems of stagnation, as partocracy, power of oligarchy, wars, international terrorism, climate change, etc.

\section{Conclusions}

Virtual modelling of Human qualitative development leap gives very short, concentrated, digitalised understanding of global path in history. It discovers main logics, directions and conditionality of human development, what is very helpful in selfimprovement and clear planning of own activities not spending time on not perspective activities.

Qualitative development approach "gives a second breath" to science of Anthropogeny on the ground of Human development spiral, as template for deeper and detail construction of whole video from Pat to Future Homo Virtualis.

The Form of Homo sapiens sapiens is the Speech as verbally encoded transferring of mental images between humans. The Content of HSS is Free creative activity as process during which Human is freeing from Obligatory work through replacing this unlovely activity to shoulders of animals, employees and automated technical systems. It has sense of freeing from manual work as progressive trend.

The next $-5^{\text {th }}$ quality of the Life - Homo Virtualis as whole spiritual - informational bodies of humans connected in a mega brain will start own path in the spiritual Universe.

It's significant, that Homo Virtualis proofs the convergence of scientific and religion approaches to future of HSS.

Discovered human development mechanism becomes the ground for creation artificial intelligence tools for large application in technical, technological and social systems.

\section{References}

Ayala, F, Cela-Conde, C. (2017) Processes in Human Evolution: The Journey from Early Hominins to Neandertals and Modern Humans. books.google.com. Oxford University Press. BibTeX Tagged XML.

Ayala, F, Cela-Conde, C. Science and Technology in Human Societies: From Tool Making to Technology. In: On Human Nature: Biology, Psychology, Ethics, Politics, and Religion. Academic Press. 2017, p.729-755. BibTeX Tagged XML.

Ayala, F. (2017) Human Evolution and Progress. In: On Human Nature: Biology, Psychology, Ethics, Politics, and Religion. Academic Press. 2017, p. 565-577. BibTeX Tagged XML.

Bogin, B, Varea, C. (2017) Evolution of the human life history. In: Kaas, J, eds. Evolution of Nervous Systems, 2nd. Academic Press. 2017;4:37-50. BibTeX Tagged XML.

Cartmill, M. A sort of revolution: Systematics and physical anthropology in the 20th century. Am J Phys
Anthropol. 2018;165(4):677-687. BibTeX Tagged XML.

Ernst Haeckel (1868) The History of Creation. New York: D. Appleton and Company.

Ernst Haeckel (1897) The Evolution of Man: A Popular Exposition of the Principal Points of Human Ontogeny and Phylogeny, Volumes 1 and 2. English Translation. New York: D. Appleton and Company.

Galway-Witham, J, Cole, J, Stringer, C. (2019) Aspects of human physical and behavioural evolution during the last 1 million years. Journal of Quaternary Science. BibTeX Tagged XML

Gintis, H, Van Schaik, C, Boehm, C. (2019) Zoon Politikon: The Evolution of Human Socio-Political Systems. Behavioural Processes. 2019;161:1730.BibTeX Tagged XML.

Gregory, William K. (1985). "The New Anthropogeny: Twenty-Five Stages of Vertebrate Evolution From Silurian Chordate to Man". Science. 77: 29-40. doi:10.1126/science.77.1985.29. PMID 17792389.

Harari, Yuval Noah (2017). Homo Deus: A Brief History of Tomorrow. London: Vintage. pp. 7576. ISBN 9781784703936. OCLC 953597984.

Chan, Eva K. F.; Timmermann, Axel; Baldi, Benedetta F.; Moore, Andy E.; Lyons, Ruth J.; Lee, Sun-Seon; Kalsbeek, Anton M. F.; Petersen, Desiree C.; Rautenbach, Hannes; Förtsch, Hagen E. A.; Bornman, M. S. Riana; Hayes, Vanessa M. (2019) Human origins in a southern African palaeo-wetland and first migrations. Nature. 2019;575(7781):185 189.

Humphrey, L, Stringer, C.(2018) Our Human Story: Where we Come From and How we Evolved. London Natural History Museum. BibTeX Tagged XML.

Jarmon, Leslie (2010). „Homo Virtualis": Virtual Worlds, Learning, and an Ecology of Embodied Interaction. International Journal of Virtual and Personal Learning Environments, v1 n1 Article 4 p38-56.

Jeste, D, Lee, E, Charles, C, Caspari, R, Gagneux, P, Glorioso, D, Miller, B, Semendeferi, K, Vogler, C, Nusbaum, H, Blazer, D. (2019).New Science of Practical Wisdom. Perspectives in Biology and Medicine.2019;62(2):216-236. BibTeX Tagged XML.

Levelt, Willem J. M. (1999). "Models of word production". Trends in Cognitive Sciences. 3 (6): 223-32. doi:10.1016/s1364-6613(99)013194. PMID 10354575.

Nick Bostrom. (2007) The Future of Humanity. Published in New Waves in Philosophy of Technology, eds. Jan-Kyrre Berg Olsen, Evan Selinger, \& Soren Riis (New York: Palgrave McMillan, 2009): 186-216]. [pdf]

Norbert Wiener (1948), Cybernetics: Or Control and Communication in the Animal and the Machine. Paris, (Hermann \& Cie) \& Camb. Mass. (MIT Press) ISBN 978-0-262-73009-9; 2nd revised ed. 1961.

Paulauskas S. (2017) Virtualics: Where did the Dialectic?/ Management - Journal of Management. Lithuania business university of applied sciences, ISSN 16487974. Klaipeda, Lithuania. 2017, № 2(31). -P.105109.

Paulauskas S., Paulauskas A.(2008) The virtualics and strategic Self-Management as tools for sustainable development. / Technological and economic development of economy, Baltic Journal on Sustainability. 2008. 14(1): 76-88.

Paulauskas, S. (1999). Self-Management Dialectics. Theory, methodology models, Monograph. Klaipeda University. Klaipeda. 
Pierre Teilhard de Chardin. (1999)The Human Phenomenon (1999), Brighton: Sussex Academic, 2003: ISBN 1-902210-30-1.

Tibayrenc, M, Ayala, F. (2017)On Human Nature: Biology, Psychology, Ethics, Politics, and Religion, 1st. Academic Press. 2017. BibTeX Tagged XML.
Tomasello, M. (2019). Becoming Human: A Theory of Ontogeny. Harvard University Press. BibTeX Tagged XML.

Varki, Ajit; Geschwind, Daniel; Eichler, Evan (2008). "Explaining human uniqueness: genome interactions with environment, behaviour and culture". Nature Reviews Genetics. 9 (10): 749-763. doi:10.1038/nrg2428. PMC 2756412.

RECEIVED: 1 January 2020

ACCEPTED: 14 May 2020

Stasys Paulauskas, Doctor of Philosophy (applied sociology), professor, establisher and head of Public Institution Strategic SelfManagement Institute (from 1991). Author and innovator of methodological systems Virtualics, Anthropogeny, Sociogeny, Technogeny, Strategic Self-Management, Responsible Energy, Sustainable Innovation, Circular Economy 3.0, Blue growth index, which are applied to fields of education, maritime, ITC, energy, business, culture, etc. trough large scientific research and innovations and participation in international programmes of UNDP GEF, Leonardo da Vinci, Erasmus, Interreg IIIa, South Baltic and Baltic Sea region. Main specialisation is introduction of Strategic Self-Management in different levels of social organisations. Baltijos pr. 123-61 LT-93224 Klaipeda, Lithuania; +370 655 39295. ssi@eksponente.lt, www.eksponente.lt 